\section{Using Social}

Media to Impart

Early Literacy

Tips to Parents

Jill Bickford

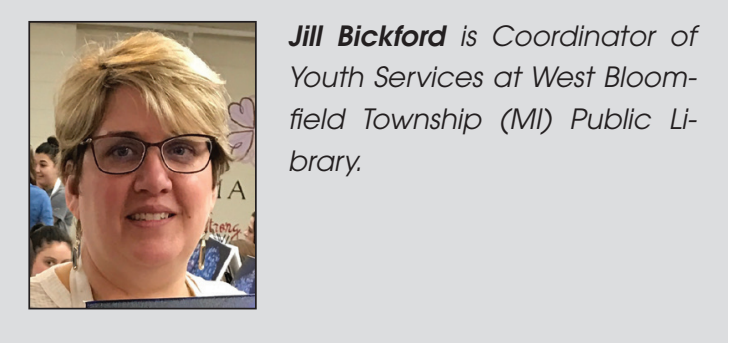

$\mathrm{L}$ ibraries are constantly working to help parents prepare their children to be readers, and we're aided, in part, by the Every Child Ready to Read (ECRR) parent education initiative.

We are always looking for new ways to reach parents of young children and convey this accessible, practical, and applicable information. We impart tips during parent workshops and storytimes, and one-on-one during patron interactions, but how do we continue to reach them once they've left the building? How do we reach those caregivers who cannot regularly come to our libraries for a variety of reasons?

Social media provides us with a simple and affordable way to do just that. Tools such as Facebook, Pinterest, Twitter, and Instagram can enable us to reach parents and provide them with an abundant, yet not overwhelming, amount of helpful and inspiring information.

A July 2015 Pew Research Center report titled Parents and Social Media found that among parents who use the Internet, 83 percent use social media. ${ }^{1}$ Among those, 83 percent of mothers and 74 percent of fathers said they receive useful information through social media, and 59 percent said they found parenting information. ${ }^{2}$ Younger parents were more likely to use Instagram; in fact, that platform was used by 35 percent of parents with children under the age of five. ${ }^{3}$ According to a report by Crowdtap, a whopping 90 percent of millennial parents find social media helpful. ${ }^{4}$

In determining which platforms to use at your library, consider surveying your users, like we did at the West Bloomfield Township (MI) Public Library in 2015. When patrons were asked what types of information they wanted to receive from the library via social media, 17 percent wanted parenting tips and 24 percent wanted early literacy activities. Prior to the survey, we mainly focused our social media posts on program promotion. After conducting our survey, however, we realized that our audience was more interested in learning tips for at home engagement with their children.

Social media allows us to communicate with parents on a regular basis with short, simple messages, mainly with pictures, keeping text to a minimum, especially on platforms such as Pinterest and Instagram. A photo or video can grab the attention of busy parents. A simple video clip of a nursery rhyme being sung or picture of Humpty Dumpty can prompt a parent to sing to a child. A picture of a child finger-painting can remind a parent of a simple activity to build fine motor skills. Additionally, social media enables libraries to reach parents beyond those who specifically follow them. When a parent shares a post, retweets, or repins, the message reaches even more parents.

At West Bloomfield, we have a separate Pinterest board as part of our Grow Up Reading initiative to offer parents, caregivers, and early childhood educators simple early literacy activities. The Pinterest board, along with our other social media accounts, is promoted on our website and print 
materials but also through word of mouth and at programs and storytimes.

Many youth services departments feel they do not have the staff resources to maintain a vibrant social media presence. Remember that your content does not need to be an original creation. Just as we do not write the books in our collections, you do not need to write original posts. There are many organizations already doing this, such as Too Small to Fail, Zero to Three, and Child Trends. Monitor information from a variety of organizations and harvest and use it as appropriate for your audience. $\leftleftarrows$

\section{References}

1. Pew Research Center, Parents and Social Media, July 16, 2015, www.pewinternet.org/2015/07/16/parents-and -social-media.

2. Ibid.

3. Ibid.

4. "Meet the (Millennial) Parents," Crowdtap, January 26, 2016, http://blog.crowdtap.it/2016/01/meet-the -millennial-parents.

\section{New from Children and Libraries}

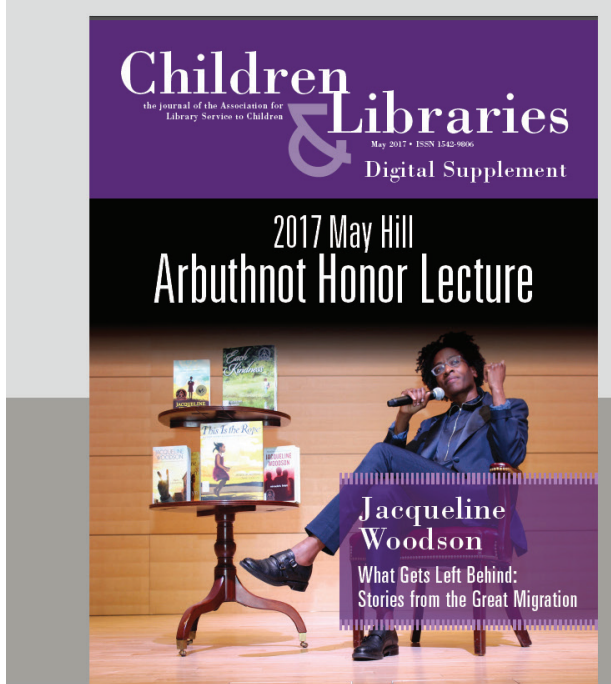

\section{Annual Spring Digital Supplement featuring the Arbuthnot Honor Lecture}

Jacqueline Woodson

What Gets Left Behind: Stories from the Great Migration

May 2017

https://journals.ala.org/cal 